\section{(6) OPEN ACCESS}

\title{
Coexistence of OSA may compensate for sleep related reduction in neural respiratory drive in patients with COPD
}

\author{
Bai-Ting He, ${ }^{1}$ Gan Lu, ${ }^{2}$ Si-Chang Xiao, ${ }^{1}$ Rui Chen, ${ }^{3}$ Joerg Steier, ${ }^{4}$ John Moxham, ${ }^{4}$ \\ Michael I Polkey, ${ }^{5}$ Yuan-Ming Luo ${ }^{1}$
}

- Additional material is published online only. To view please visit the journal online (http://dx.doi.org/10.1136/ thoraxjnl-2016-208467)

For numbered affiliations see end of article.

\section{Correspondence to}

Professor YM Luo, State Key Laboratory of Respiratory

Disease, 151 Yanjiang Road Guangzhou 510120, China; yuanminglu09431@yahoo.co. uk or

Dr R Chen, Department of Respiratory Medicine, Second Affiliated Hospital of Soochow University, Suzhou, China; chenruigood@126.com

$\mathrm{BH}, \mathrm{GL}$ and SX contributed equally to this work.

Received 9 February 2016 Revised 9 September 2016 Accepted 5 October 2016 Published Online First 2 November 2016

\section{ABSTRACT}

Background The mechanisms underlying sleep-related hypoventilation in patients with coexisting COPD and obstructive sleep apnoea (OSA), an overlap syndrome, are incompletely understood. We compared neural respiratory drive expressed as diaphragm electromyogram $\left(E M G_{d i}\right)$ and ventilation during stage 2 sleep in patients with COPD alone and patients with overlap syndrome. Methods EMG di and airflow were recorded during full polysomnography in 14 healthy subjects, 14 patients with OSA and 39 consecutive patients with COPD. The ratio of tidal volume to $E \mathrm{MG}_{\mathrm{di}}$ was measured to indirectly assess upper airway resistance.

Results Thirty-five patients with COPD, 12 healthy subjects and 14 patients with OSA completed the study. Of 35 patients with COPD, 19 had COPD alone (FEV $38.5 \% \pm 16.3 \%$ ) whereas 16 had an overlap syndrome (FEV $47.5 \pm 16.2 \%$, AHI 20.5 \pm 14.1 events/hour). Ventilation $\left(V_{E}\right)$ was lower during stage 2 sleep than wakefulness in both patients with COPD alone $(8.6 \pm 2.0$ to $6.5 \pm 1.5 \mathrm{~L} / \mathrm{min}, \mathrm{p}<0.001)$ and those with overlap syndrome $(8.3 \pm 2.0$ to $6.1 \pm 1.8 \mathrm{~L} / \mathrm{min})$. Neural respiratory drive from wakefulness to sleep decreased significantly for patients with COPD alone $(29.5 \pm 13.3 \%$ to 23.0 $\pm 8.9 \%$ of maximal, $p<0.01$ ) but it changed little in those with overlap syndrome. The ratio of tidal volume to $E M G_{d i}$ was unchanged from wakefulness to sleep in patients with COPD alone and healthy subjects but was significantly reduced in patients with OSA or overlap syndrome $(p<0.05)$.

Conclusions Stage 2 sleep-related hypoventilation in COPD alone is due to reduction of neural respiratory drive, but in overlap syndrome it is due to increased upper airway resistance.

\section{INTRODUCTION}

COPD is a common condition and patients with COPD are subject to hypoxaemia or even respiratory failure during sleep because of hypoventilation. ${ }^{1}{ }^{2}$ In prior reports we showed that this hypoventilation, in the absence of upper airway obstruction was due to a reduction in neural respiratory drive to the respiratory muscles as measured by the diaphragm electromyogram $\left(E M G_{\mathrm{di}}\right){ }^{2}{ }^{3}$ Obstructive sleep apnoea (OSA) is characterised by repeated partial or complete collapse of the upper airway leading to increased upper airway resistance and arousal from sleep

\section{Key messages}

What is the key question?

- The mechanisms underlying sleep-related hypoventilation in patients with coexistent COPD and obstructive sleep apnoea (OSA), an overlap syndrome, are unknown.

\section{What is the bottom line?}

- This study shows that sleep-related hypoventilation in patients with overlap syndrome is due to an increase in upper airway resistance associated with OSA rather than reduction of neural respiratory drive associated with COPD.

\section{Why read on?}

- Sleep-related hypoventilation in patients with COPD alone mainly occurs because of a decrease in neural respiratory drive whereas it is mainly a result of an increase in upper airway resistance in patients with overlap syndrome.

which are associated with increased neural respiratory drive. ${ }^{45}$

It has been previously reported that nocturnal oxygen desaturation is more severe in patients with COPD and OSA, a phenotype termed the 'overlap syndrome', than those with COPD alone. ${ }^{6}$ However, this view is mainly based on the results derived from patients with mild or moderate COPD and predominant OSA who are often obese $^{78}$ and may not be the case for patients with more severe COPD. ${ }^{9}$ In contrast to the hypoventilation in patients with COPD, OSA is characterised by increased upper airway resistance and is associated with an increase in neural respiratory drive. $^{24510}$ If patients with severe COPD develop OSA, the sleep-related reduction in neural respiratory drive associated with COPD could be offset by an increase in neural respiratory drive due to increased upper airway resistance. Consequently, ventilation in patients with severe COPD may not further decrease when COPD and mild or modest OSA occur together.

The $\mathrm{EMG}_{\mathrm{di}}$ recorded from a multipair oesophageal electrode can be used to assess neural respiratory drive, ${ }^{2} 451011$ and upper airway resistance 
can be inferred by the ratio of the tidal volume $\left(V_{\mathrm{T}}\right)$ to $\mathrm{EMG}_{\mathrm{di}}$ $\left(\mathrm{V}_{\mathrm{T}} / \mathrm{EMG}_{\mathrm{di}}\right)$ assuming that lung mechanics and lower airway resistance remain constant in wakefulness and sleep. ${ }^{2}$ Here we aimed to investigate the underlying mechanisms of hypoventilation during sleep in patients with COPD alone and patients with overlap syndrome by comparing neural respiratory drive and ventilation. The data from 10 of the patients with COPD alone and 10 healthy subjects has previously been reported; these were the participants with complete datasets from that report. $^{2}$

\section{METHODS \\ Subjects}

Thirty-nine consecutive patients with COPD from the outpatient clinic of Guangzhou Institute of Respiratory Disease were studied, including 10 patients whose data were reported previously. ${ }^{2}$ Exclusion criteria were a known diagnosis of OSA before the study, clinically significant coexisting diseases including cardiovascular and neuromuscular disease, an acute exacerbation of COPD in the preceding month, $\mathrm{FEV}_{1}<20 \%$ predicted, and use of long-term oxygen therapy. Usual medications including inhaled bronchodilators were allowed for all the patients. Fourteen healthy subjects and 14 patients with OSA were also studied; as noted 10 of the healthy subjects had appeared in our prior report. ${ }^{2}$ The study was approved by the Ethics Committee of the First Affiliated Hospital of Guangzhou Medical University and all subjects gave written informed consent.

\section{Lung function tests}

Spirometry (Cosmed Micro Quark, Cosmed, Italy) was performed on the same night as polysomnography. Measurements were repeated until maximal reproducible values of $\mathrm{FEV}_{1}$ were achieved with variation of less than $150 \mathrm{ml}$ between tests. The modified Medical Research Council dyspnoea scale (mMRC) was also recorded before polysomnography.

\section{Oesophageal electrode and its positioning}

A soft fine catheter with an external diameter of $1.6 \mathrm{~mm}$ was used to record the $\mathrm{EMG}_{\mathrm{di}}$. The catheter had 10 metal coils which provided five pairs of recording electrodes was used to record the $\mathrm{EMG}_{\mathrm{di}}$. The oesophageal electrode was passed through the nose into the stomach and was carefully positioned based on the $\mathrm{EMG}_{\mathrm{di}}$ amplitude recorded simultaneously from the five pairs of electrodes, as reported previously. ${ }^{4}{ }^{12}$ Briefly the position of the electrode catheter was judged to be optimal when electrode 5 was located at the level of the diaphragm confirmed by the amplitude of $\mathrm{EMG}_{\mathrm{di}}$ activity being greatest in pairs 1 and 5, and smallest in pair 3 during inspiration. When the electrode catheter was in the optimal position, it was securely taped at the nose. The $\mathrm{EMG}_{\mathrm{di}}$ signals were amplified and band-pass filtered between $20 \mathrm{~Hz}$ and $1 \mathrm{kHz}$ (RA-8, Yinghui Medical Technology Co., Guangzhou, China).

\section{Measurement of maximal $\mathrm{EMG}_{\mathrm{di}}$}

Maximal $E G_{\mathrm{di}}$ was recorded during two manoeuvres: maximal inspiration to total lung capacity (TLC) and maximal inspiration against a closed airway at functional residual capacity for $3 \mathrm{~s}$. Each manoeuvre was repeatedly performed until subjects were able to master the techniques. More than three maximal efforts, with an interval of $30 \mathrm{~s}$ or more between them, were recorded for analysis and the largest single value was considered maximal.

\section{Polysomnography}

Full overnight polysomnograms including the EEG (C3-A2, C4-A1), left and right electro-oculograms (EOG), submental electromyogram $\left(\mathrm{EMG}_{\mathrm{chin}}\right)$, airflow, snoring, body position, oxygen saturation and end-tidal $\mathrm{CO}_{2}$ were recorded. Airflow was recorded with a pneumotachgraph connected to a full facemask, and integrated to produce volume. All signals were recorded simultaneously using a Powerlab recording system (ADInstruments, Castle Hill, Australia). The sampling rate was $2 \mathrm{kHz}$ for $E M G_{\mathrm{di}}$ and $200 \mathrm{~Hz}$ for other signals. $E \mathrm{MG}_{\mathrm{di}}$ was recorded before and during sleep.

\section{Analysis of data}

Conventional polysomnography was manually analysed based on standard criteria. ${ }^{13}$ An obstructive apnoea event was defined as absence of airflow for longer than $10 \mathrm{~s}$, while there was phasic inspiratory $\mathrm{EMG}_{\mathrm{di}} \cdot{ }^{10}{ }^{13} \mathrm{~A}$ hypopnoea event was defined as reduction of airflow of more than $30 \%$ for longer than $10 \mathrm{~s}$ associated with $\geq 3 \%$ desaturation or the event being associated with arousal. ${ }^{13}$ Overlap syndrome was defined as apnoea hypopnoea index $(\mathrm{AHI}) \geq 5$ events/hour in the presence of COPD. Clinically significant sleep-related desaturation was defined as $\mathrm{SaO}_{2}<90 \%$ which lasted longer than $5 \mathrm{~min}$. The root mean square of the $E M G_{\mathrm{di}}$ was calculated by computer with a time constant of $100 \mathrm{~ms}$. The root mean square reported was that from the electrode pair with the largest $\mathrm{EMG}_{\mathrm{di}}$ amplitude for each breathing cycle. To avoid the influence of the electrocardiogram on the $\mathrm{EMG}_{\mathrm{di}}$, root mean square was measured from segments between QRS complexes. A ratio of $\mathrm{V}_{\mathrm{T}}$ to root mean square of $E M G_{\mathrm{di}}\left(\mathrm{V}_{\mathrm{T}} / \mathrm{EMG}_{\mathrm{di}}\right)$ of each breath was used to assess upper airway resistance. $^{2}$ Data were selected during stable breathing without respiratory events unless stated otherwise. Ten minutes of data before sleep and at least $14 \mathrm{~min}$ during stage 2 in the supine position were selected for analysis.

To further confirm that the $\mathrm{V}_{\mathrm{T}} / \mathrm{EMG}_{\mathrm{di}}$ could be used to assess change in upper airway resistance from wakefulness to sleep, we measured $\mathrm{V}_{\mathrm{T}} / \mathrm{EMG}_{\mathrm{di}}$ during wakefulness, during snoring and hypopnoea events in patients with overlap syndrome. At least 50 breathing cycles were measured for each condition.

Data were presented as mean \pm SD. The Wilcoxon rank sum test and Kruskal-Wallis test followed by Dunn's test were used to test for differences between groups as appropriate. Statistical significance was determined by $\mathrm{p}<0.05$.

\section{RESULTS}

Four patients with COPD and two healthy subjects could not tolerate the oesophageal catheter or full face mask connected to the pneumotachgraph, therefore final data were derived from 35 patients with COPD, 12 healthy subjects and 14 patients with OSA (see table 1 and online supplementary table E-1). Using the above criteria 16 of the patients with COPD were found to have overlap syndrome $\left(\mathrm{FEV}_{1} 47.5 \pm 16.2 \%\right.$; AHI 20.5 \pm 14.1 events/ hour) and 19 patients had COPD alone $\left(\mathrm{FEV}_{1} 38.5 \pm 16.3 \%\right.$; AHI 1.9 \pm 1.6$)$. The body mass index (BMI) in patients with COPD alone $\left(19.9 \pm 2.7 \mathrm{~kg} / \mathrm{m}^{2}\right)$ was significantly lower than that in patients with overlap syndrome $\left(23.5 \pm 3.8 \mathrm{~kg} / \mathrm{m}^{2}\right)$ $(p<0.05)$. The $\mathrm{FEV}_{1}$ in patients with COPD alone was not significantly different from that in patients with overlap syndrome $(38.5 \% \pm 16.3 \%$ vs $47.5 \% \pm 16.2 \%, \mathrm{p}>0.05)$. The respiratory events in patients with overlap syndrome were predominantly hypopnoea rather than apnoea, except for subject 1 (see table 1 and online supplementary table E-2). Overall, the ratio of hypopnoea to apnoea events in patients with overlap syndrome 
Table 1 Basic information for all subjects

\begin{tabular}{|c|c|c|c|c|}
\hline Characteristics & COPD $(n=19)$ & $\begin{array}{l}\text { Overlap } \\
(n=16)\end{array}$ & $\begin{array}{l}\text { Normal } \\
(n=12)\end{array}$ & $\begin{array}{l}\text { OSA } \\
(n=14)\end{array}$ \\
\hline Age (years) & $62.0 \pm 9.2$ & $61.5 \pm 10.2$ & $58.1 \pm 8.3$ & $55.8 \pm 8.9$ \\
\hline BMI $\left(\mathrm{kg} / \mathrm{m}^{2}\right)$ & $19.9 \pm 2.7$ & $23.5 \pm 3.8$ & $22.3 \pm 2.8$ & $25.8 \pm 3.7$ \\
\hline FVC\%pred & $73.7 \pm 19.9$ & $68.5 \pm 17.4$ & $98.6 \pm 9.6$ & $100 \pm 12.6$ \\
\hline $\mathrm{FEV}_{1} \%$ pred & $38.5 \pm 16.3$ & $47.5 \pm 16.2$ & $98.1 \pm 9.2$ & $99.1 \pm 14.6$ \\
\hline $\mathrm{FEV}_{1} / \mathrm{FVC} \%$ & $41.3 \pm 11.2$ & $54.6 \pm 11.4$ & $79.6 \pm 3.4$ & $80.4 \pm 6.3$ \\
\hline mMRC & $1.8 \pm 0.9$ & $1.6 \pm 0.5$ & $0 \pm 0$ & $0 \pm 0$ \\
\hline$E M G_{\text {di-max }}(\mu \mathrm{V})$ & $176.9 \pm 72.1$ & $192.3 \pm 56.6$ & $156.1 \pm 50.3$ & $166.2 \pm 40.8$ \\
\hline $\mathrm{EMG}_{\text {di-rest }}(\mu \mathrm{V})$ & $29.5 \pm 13.3$ & $29.3 \pm 15.8$ & $12.6 \pm 3.7$ & $14.2 \pm 7.9$ \\
\hline $\begin{array}{l}\text { AHI (events/ } \\
\text { hour) }\end{array}$ & $1.9 \pm 1.6$ & $20.5 \pm 14.1$ & $1.6 \pm 1.4$ & $25.6 \pm 18$ \\
\hline TST (hours) & $4.4 \pm 2.0$ & $3.9 \pm 1.8$ & $4.2 \pm 1.4$ & $5.6 \pm 1.8$ \\
\hline Rest $\mathrm{SaO}_{2}(\%)$ & $96.8 \pm 1.4$ & $97.1 \pm 1.3$ & $98.0 \pm 1.0$ & $96.9 \pm 0.7$ \\
\hline Mean $\mathrm{SaO}_{2}(\%)$ & $96.0 \pm 1.6$ & $95.8 \pm 1.4$ & $97.6 \pm 0.9$ & $96.1 \pm 1.4$ \\
\hline $\mathrm{Mini} \mathrm{SaO}_{2}(\%)$ & $90.6 \pm 5.3$ & $90.9 \pm 3.9$ & $93.6 \pm 2.4$ & $85.3 \pm 8.7$ \\
\hline TB90\% & $4.7 \pm 5.5$ & $0.4 \pm 0.5$ & - & $2.2 \pm 5.5$ \\
\hline
\end{tabular}

was 4.4:1. COPD alone and overlap syndrome groups were similar to each other but, as expected, had significantly greater dyspnoea compared with healthy subjects and patients with OSA $(\mathrm{p}<0.001)$. The maximal $\mathrm{EMG}_{\mathrm{di}}$ was similar between groups and was $176.9 \pm 72.1,192.3 \pm 56.6,156.1 \pm 50.3,166.2$ $\pm 40.8 \mu \mathrm{V}$ for COPD alone, patients with overlap syndrome, healthy subjects and patients with OSA $(\mathrm{p}>0.05)$, respectively.

The mean $\mathrm{SaO}_{2} \%$ over the entire sleep period was $96.8 \pm 1.4$, $97.1 \pm 1.3,98.0 \pm 1.0$ and $96.9 \pm 0.7$ during wakefulness and 96.0 $\pm 1.6,95.8 \pm 1.4,97.6 \pm 0.9$ and $96.1 \pm 1.4$ during sleep for patients with COPD alone, patients with overlap syndrome, healthy subjects and patients with OSA, respectively. COPD alone and overlap syndrome groups were similar to each other but had a lower mean minimal $\mathrm{SaO}_{2} \%$ during overnight sleep compared with healthy subjects (see table 1 and online supplementary table E-2). Mean minimal $\mathrm{SaO}_{2} \%$ in patients with OSA was lower than those in the other three groups. Three of 19 (16\%) patients with COPD alone developed $\mathrm{SaO}_{2}<90 \%$ for longer than $5 \mathrm{~min}$, whereas no subjects in both the patients with overlap syndrome and the healthy subjects developed significant oxygen desaturation (see online supplementary table E-2).

\section{Ventilation in patients with COPD, patients with overlap syndromes, healthy subjects and those with OSA during wakefulness and sleep}

$\mathrm{V}_{\mathrm{E}}$ was similar between groups and was 8.6 $\pm 2.0,8.3 \pm 2.0,8.3$ \pm 1.6 and $8.0 \pm 2.7 \mathrm{~L} / \mathrm{min}$ for patients with COPD alone, patients with overlap syndromes, healthy subjects and patients with OSA during wakefulness $(p>0.05)$. $V_{E}$ decreased significantly from wakefulness to non-rapid eye movement (NREM) sleep for patients with COPD alone $(8.6 \pm 2.0$ to $6.5 \pm 1.5 \mathrm{~L} /$ min, $\mathrm{p}<0.001)$, patients with overlap syndrome $(8.3 \pm 2.0$ to 6.1 $\pm 1.8 \mathrm{~L} / \mathrm{min}, \mathrm{p}<0.001)$ and patients with OSA $(8.0 \pm 2.7$ to 6.3 $\pm 1.9 \mathrm{~L} / \mathrm{min}, \mathrm{p}<0.01$ ), although the change in $\mathrm{VE}$ failed to attain statistical significance between wakefulness and NREM sleep in healthy subjects $(8.3 \pm 1.6$ to $7.5 \pm 1.3 \mathrm{~L} / \mathrm{min}, \mathrm{p}=0.07)$. The decrease in $\mathrm{V}_{\mathrm{E}}$ from wakefulness to sleep was similar between patients with COPD and patients with overlap syndrome $(24 \%$ vs $27 \%, \mathrm{p}>0.05)$, but it was greater in both groups than that observed in healthy subjects $(10 \%), \mathrm{p}<0.05$. Change in $V_{E}$ was almost proportional to change in $V_{T}$ in patients with COPD, patients with overlap syndrome and patients with OSA (table 2, figures 1 and 2).

Neural respiratory drive decreased significantly in patients with COPD alone $(29.5 \pm 13.3 \%$ vs $23.0 \pm 8.9 \%$ of maximal $\mathrm{EMG}_{\mathrm{di}}, \mathrm{p}<0.01$ ), but increased significantly in patients with OSA $\left(14.2 \pm 7.9 \%\right.$ vs $23.4 \pm 10.8 \%$ of maximal $\left.\mathrm{EMG}_{\mathrm{di}}\right)$ from wakefulness to NREM sleep. However, neural respiratory drive changed little from wakefulness to stage 2 sleep in patients with overlap syndrome $(29.3 \pm 15.8 \%$ vs $27.3 \pm 14.7 \%$ of maximal $\left.\mathrm{EMG}_{\mathrm{di}}, \mathrm{p}>0.05\right)$ and in healthy subjects $(12.6 \pm 3.7 \%$ vs 12.2 $\pm 3.3 \%$ of maximal $\left.\mathrm{EMG}_{\mathrm{di}}, \mathrm{p}>0.05\right)$. Respiratory rate also changed little between wakefulness and NREM sleep in all four groups $(p>0.05) . V_{\mathrm{T}} / \mathrm{EMG}_{\mathrm{di}}$ was similar between wakefulness and NREM sleep in both healthy subjects $(0.69 \pm 0.18$ vs 0.69 $\pm 0.20)$ and patients with COPD alone $(0.39 \pm 0.23$ vs 0.37 \pm 0.21 ) but it decreased significantly from wakefulness to sleep in patients with overlap syndrome $(0.35 \pm 0.21$ vs $0.28 \pm 0.19$, $\mathrm{p}<0.05)$ and patients with OSA $(0.56 \pm 0.24$ vs $0.28 \pm 0.13$, $\mathrm{p}<0.01$ ) (see table 2 and online supplementary tables E-3 and E-4, and supplementary figure E-1).

In patients with overlap syndrome the $\mathrm{V}_{\mathrm{T}} / \mathrm{EMG}_{\mathrm{di}}$ decreased from the state of wakefulness, to sleep in which snoring was recorded $(0.35 \pm 0.21$ vs $0.24 \pm 0.14, \mathrm{p}<0.001)$ and further decreased during stage 2 hypopnoea events $(0.15 \pm 0.12$, $\mathrm{p}<0.001$ ) (table 3; data for stage 2 sleep with or without snoring are shown in online supplementary table E-4).

\section{DISCUSSION}

In the present study we show that unlike healthy subjects who exhibited a small (approximately 10\%) difference between NREM sleep and wakefulness, $V_{E}$ was lower in stage 2 sleep than wakefulness in patients with COPD alone and those with overlap syndrome or OSA. In patients with overlap syndrome neural respiratory drive was similar between NREM sleep and wakefulness. However, neural respiratory drive from wakefulness to stage 2 sleep increased in patients with OSA but decreased in those with COPD alone, suggesting that mild or moderate OSA can partially compensate for reduction of neural respiratory drive inherent to COPD and certainly does not seem to worsen hypoventilation associated with COPD.

\section{Methodological issues}

This is the first study to simultaneously record ventilation and neural respiratory drive from patients with COPD alone and patients with an overlap syndrome. Some studies have previously assessed ventilation during sleep using respiratory inductance plethysmography, ${ }^{14-17}$ which can be inaccurate particularly in patients with COPD. ${ }^{18}{ }^{19}$ Becker et $a l^{18}$ used a pneumotachograph to measure ventilation during sleep in patients with COPD, but the pneumotachograph in their study was connected with a nasal mask rather than a full-face mask, leading to a potential underestimate of ventilation if patients breathed through the mouth. Using a full face mask to quantify ventilation we found a larger reduction of ventilation in NREM than that reported by Becker et al ${ }^{18}$ using a nasal mask.

The $\mathrm{FEV}_{1}$ in patients with overlap syndrome was numerically, although not statistically, higher than that in patients with COPD alone. Because obesity is an important factor contributing to development of OSA and because COPD is a chronic wasting disease sometimes associated with weight loss as disease progresses, it could be argued that patients with severe COPD 
Table 2 Diaphragm EMG, ventilation during wakefulness and NREM sleep

\begin{tabular}{|c|c|c|c|c|c|c|c|c|}
\hline \multirow[b]{2}{*}{ Characteristics } & \multicolumn{4}{|l|}{ COPD $(n=19)$} & \multicolumn{4}{|c|}{ Overlap $(n=16)$} \\
\hline & Wakefulness & NREM & $\triangle \%$ & p Value & Wakefulness & NREM & $\triangle \%$ & p Value \\
\hline $\mathrm{EMG}_{\mathrm{di}} \% \max$ & $29.5 \pm 13.3$ & $23.0 \pm 8.9$ & 22 & 0.006 & $29.3 \pm 15.8$ & $27.3 \pm 14.7$ & 7 & 0.38 \\
\hline$V_{E}(L)$ & $8.6 \pm 2.0$ & $6.5 \pm 1.5$ & 24 & $<0.001$ & $8.3 \pm 2.0$ & $6.1 \pm 1.8$ & 27 & 0.001 \\
\hline $\mathrm{V}_{\mathrm{T}}(\mathrm{L})$ & $0.47 \pm 0.11$ & $0.37 \pm 0.09$ & 22 & 0.001 & $0.47 \pm 0.11$ & $0.36 \pm 0.10$ & 24 & 0.001 \\
\hline $\mathrm{V}_{\mathrm{T}} / \mathrm{EMG}_{\mathrm{di}}$ & $0.39 \pm 0.23$ & $0.37 \pm 0.21$ & 5 & 0.92 & $0.35 \pm 0.21$ & $0.28 \pm 0.19$ & 20 & 0.041 \\
\hline $\mathrm{ETCO}_{2}(\%)$ & $4.5 \pm 0.5$ & $4.5 \pm 0.6$ & 0 & 0.89 & $4.7 \pm 0.7$ & $4.7 \pm 0.8$ & 0 & 0.48 \\
\hline \multirow[t]{2}{*}{$\mathrm{RR}$} & $18.4 \pm 3.1$ & $17.8 \pm 2.1$ & 3 & 0.33 & $17.6 \pm 1.7$ & $17.2 \pm 2.9$ & 2 & 0.35 \\
\hline & \multicolumn{4}{|l|}{ Normal $(n=12)$} & \multicolumn{4}{|l|}{ OSA $(n=14)$} \\
\hline $\mathrm{EMG}_{\mathrm{di}} \% \max$ & $12.6 \pm 3.7$ & $12.2 \pm 3.3$ & 3 & 0.84 & $14.2 \pm 7.9$ & $23.4 \pm 10.8$ & 65 & 0.001 \\
\hline$V_{E}(L)$ & $8.3 \pm 1.6$ & $7.5 \pm 1.3$ & 10 & 0.07 & $8.0 \pm 2.7$ & $6.3 \pm 1.9$ & 21 & 0.006 \\
\hline $\mathrm{V}_{\mathrm{T}}(\mathrm{L})$ & $0.50 \pm 0.09$ & $0.49 \pm 0.10$ & 2 & 0.56 & $0.48 \pm 0.16$ & $0.39 \pm 0.10$ & 19 & 0.008 \\
\hline $\mathrm{V}_{\mathrm{T}} / \mathrm{EMG}_{\mathrm{di}}$ & $0.69 \pm 0.18$ & $0.69 \pm 0.20$ & 0 & 0.91 & $0.56 \pm 0.24$ & $0.28 \pm 0.13$ & 49 & 0.001 \\
\hline $\mathrm{ETCO}_{2}(\%)$ & $4.8 \pm 0.3$ & $5.0 \pm 0.3$ & 4 & 0.002 & $4.5 \pm 0.8$ & $4.6 \pm 0.9$ & 3 & 0.18 \\
\hline RR & $16.7 \pm 2.3$ & $15.6 \pm 2.3$ & 7 & 0.10 & $16.6 \pm 3.0$ & $16.0 \pm 2.3$ & 4 & 0.27 \\
\hline
\end{tabular}

$\triangle \%$, percentage change compared with wakefulness; $\mathrm{EMG}_{\mathrm{di}} \% \mathrm{max}$, percentage of maximal $\mathrm{EMG}_{\mathrm{di}}$ ETCO ${ }_{2}$, end-tidal $\mathrm{CO}_{2}$; NREM, non-rapid eye movement; $\mathrm{p}$ value, comparison of wakefulness and NREM; RR, respiratory rate; $V E$, minute ventilation; VT, tidal volume; $V T / E M G_{d i}$, the ratio of tidal volume to peak root mean square of EMG

are less likely to develop OSA because of weight loss. However the current dataset (by showing patients with COPD with polysomnographically proven OSA) shows that this conjecture is insufficient to prevent OSA in patients with COPD. ${ }^{20} 21$ However we note that while there was no statistically significant difference in $\mathrm{FEV}_{1}$ between patients with COPD alone and those with overlap syndrome, type II error cannot be absolutely excluded given the small numbers dictated by a physiological study of this nature. We would also point out that the similarity in mMRC score and $\mathrm{EMG}_{\mathrm{di}}$ at rest between patients with COPD alone and those with overlap syndrome also suggests the severity of airway obstruction between the two groups is similar. In the present study, the prevalence of overlap syndrome (46\%) seems to be high for a COPD cohort study, in particular for those with low BMI. However, a high prevalence of overlap syndrome has recently been reported. ${ }^{9}{ }^{21}$ Unlike Caucasian patients with COPD, ${ }^{7-9}$ the BMI in Chinese patients with COPD is usually low as previously reported. ${ }^{22}$ A high prevalence of overlap syndrome $(46 \%)$ in the COPD cohort study, despite the low BMI, may thus be attributable to Asiatic craniofacial morphology. 23

Oesophageal pressure combined with airflow recordings has recently been used to quantify upper airway resistance. ${ }^{24}$ However, oesophageal pressure is influenced by lung volume and airflow and thus has a potential limitation in the assessment of upper airway resistance in patients with OSA which is characterised by changes in lung volume and airflow. Classically a catheter positioned in the pharynx has been used to measure upper airway resistance by measurement of pharyngeal pressure. ${ }^{25} 26$ However, upper airway resistance derived from measurement of pharyngeal pressure is a difficult technique and may be variable during both wakefulness ${ }^{19}$ and sleep. ${ }^{26}$ Besides providing data regarding neural respiratory drive, $\mathrm{EMG}_{\mathrm{di}}$ has an advantage over oesophageal pressure in the assessment of upper airway resistance because it is independent of change in airflow and lung volume. ${ }^{27} 28$ Normally, $\mathrm{V}_{\mathrm{T}}$ is achieved in response to

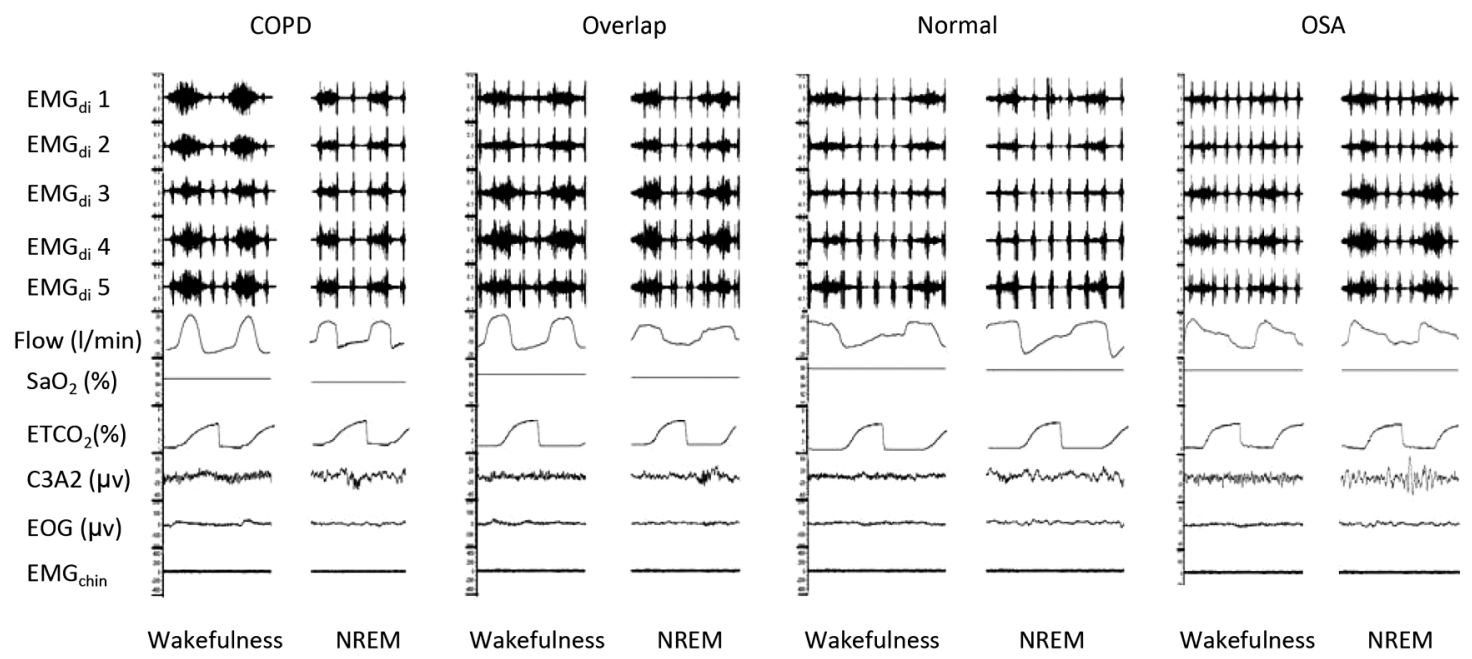

Figure 1 Diaphragm electromyogram (EMG) recording from five pairs of oesophageal electrodes and airflow from pneumotachography during polysomnography in patients with COPD alone, patients with overlap syndrome, normal subjects and patients with obstructive sleep apnoea (OSA). Diaphragm EMG decreases in patients with COPD alone but increases in patients with OSA from wakefulness to sleep, whereas it changes little in patients with overlap syndrome and in normal subjects. 

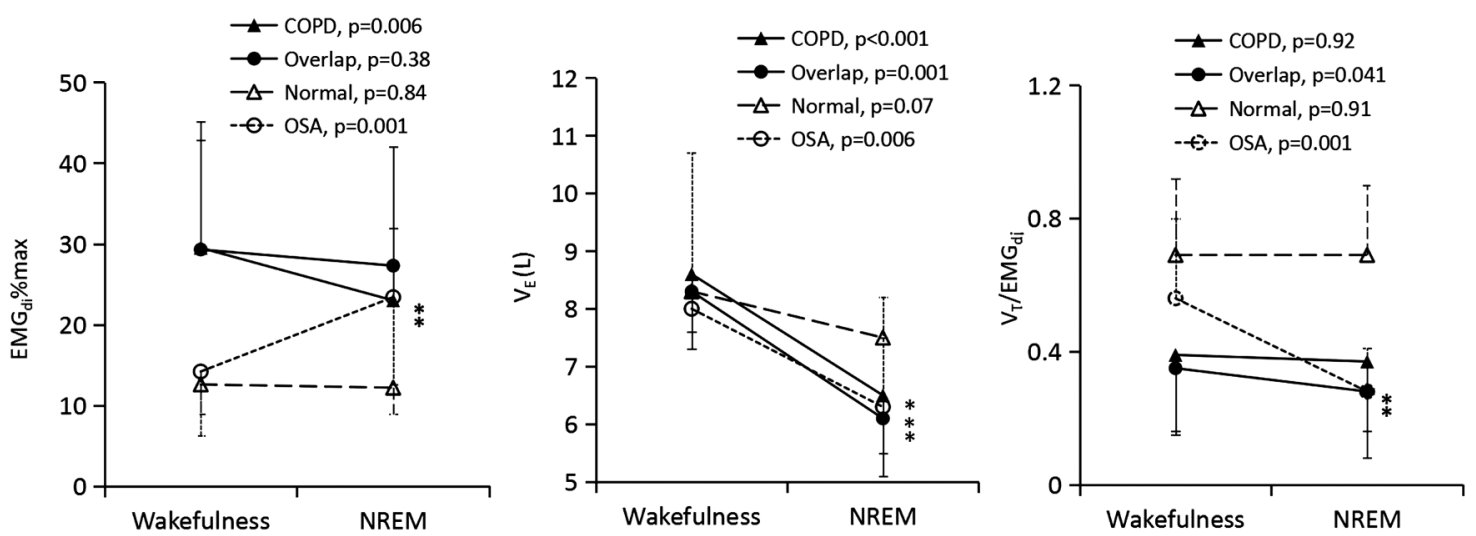

Figure 2 Electromyogram (EMG) di $_{i}$ (left panel), ventilation (middle panel) and the $\mathrm{V}_{\mathrm{T}} / \mathrm{EMG}_{\mathrm{di}}$ (right panel) in patients with COPD alone, overlap syndrome, normal subjects and patients with obstructive sleep apnoea (OSA). Ventilation decreases from wakefulness to sleep in all four groups but only in patients with COPD, overlap syndrome and OSA is the reduction statistically significant. EMG $\mathrm{di}_{\mathrm{di}}$ decreases in patients with COPD alone but increases in patients with OSA from wakefulness to non-rapid eye movement (NREM) sleep, whereas it remains the same in normal subjects and patients with overlap syndrome. $\mathrm{V}_{\mathrm{T}} / \mathrm{EMG}_{\mathrm{di}}$ decreases from wakefulness to sleep in patients with overlap syndrome and those with OSA but it changes little in normal subjects and patients with COPD alone. The decrease in ventilation is associated with a reduction of EMG $\mathrm{di}_{\mathrm{i}}$ in patients with COPD alone whereas ventilation reduction is associated with decreased $\mathrm{V}_{\mathrm{T}} / \mathrm{EMG}_{\mathrm{di}}$ in patients with overlap syndrome and those with OSA.

neural respiratory drive reflected by $\mathrm{EMG}_{\mathrm{di}}$ after overcoming total respiratory resistance, including elastic recoil of the lung, lower airway resistance and upper airway resistance. $\mathrm{V}_{\mathrm{T}} / \mathrm{EMG}_{\mathrm{di}}$ reflects changes in upper airway resistance if lung mechanics and lower airway resistance remain the same; ${ }^{2}$ one limitation of our study which should therefore be acknowledged is that lung volumes were not measured during sleep. OSA is characterised by an increase in upper airway resistance from wakefulness to snoring and a further increase to hypopnoea. In line with this concept, $\mathrm{V}_{\mathrm{T}} / \mathrm{EMG}_{\mathrm{di}}$ decreases significantly from wakefulness to snoring and further decreases to hypopnoea in patients with overlap syndrome, which supports using change in $\mathrm{V}_{\mathrm{T}} / \mathrm{EMG}_{\mathrm{di}}$ to assess changes in upper airway resistance.

\section{Significance of findings}

This study shows that neural drive decreases from the state of wakefulness to sleep in patients with COPD alone, as previously reported. ${ }^{2} 319$ It may be expected that neural respiratory drive in patients with overlap syndrome would also decrease from wakefulness to sleep, but we found that this is not the case, consistent with our prior report that obstructive respiratory events are associated with increased neural respiratory drive..$^{10}$ Several studies suggest that the increased neural respiratory drive during sleep is directly related to the presence of increased upper airway resistance since neural respiratory drive decreases when airway resistance is offset by, for example, treatment with continuous positive airway pressure ${ }^{29}$ or inhalation of Heliox $(76 \%$

Table 3 Diaphragm EMG $\left(\mathrm{EMG}_{\mathrm{di}}\right)$, tidal volume $\left(\mathrm{V}_{\mathrm{T}}\right)$ and the efficacy of neural respiratory drive $\left(\mathrm{V}_{\mathrm{T}} / \mathrm{EMG}_{\mathrm{di}}\right)$ during wakefulness, snoring and hypopnoea in patients with overlap syndrome

\begin{tabular}{|c|c|c|c|c|c|c|c|c|c|}
\hline \multirow[b]{2}{*}{ Overlap subjects } & \multicolumn{3}{|l|}{$\mathrm{EMG}_{\mathrm{d} /} / \mathrm{max} \%$} & \multicolumn{3}{|l|}{$\mathrm{V}_{\mathrm{T}}(\mathrm{mL} / \mathrm{kg})$} & \multicolumn{3}{|l|}{$\mathrm{V}_{\mathrm{T}} / \mathrm{EMG}_{\mathrm{di}}$} \\
\hline & Wakefulness & Snoring & Hypopnoea & Wakefulness & Snoring & Hypopnoea & Wakefulness & Snoring & Hypopnoea \\
\hline 1 & 49.0 & 54.7 & 48.1 & 5.1 & 4.0 & 1.2 & 0.10 & 0.07 & 0.02 \\
\hline 2 & 23.1 & 25.2 & 25.4 & 5.8 & 4.1 & 2.6 & 0.25 & 0.16 & 0.10 \\
\hline 3 & 28.1 & 37.8 & 35.3 & 10.2 & 7.5 & 3.2 & 0.36 & 0.20 & 0.09 \\
\hline 4 & 58.3 & 50.8 & 52.8 & 5.6 & 4.3 & 1.9 & 0.10 & 0.08 & 0.04 \\
\hline 5 & 21.0 & 18.2 & 14.8 & 9.3 & 6.9 & 5.1 & 0.44 & 0.38 & 0.34 \\
\hline 6 & 31.3 & 22.3 & 12.1 & 5.9 & 8.3 & 2.4 & 0.19 & 0.37 & 0.20 \\
\hline 7 & 17.1 & 23.4 & 22.8 & 9.5 & 7.5 & 4.1 & 0.56 & 0.32 & 0.18 \\
\hline 8 & 48.9 & 38.7 & 39.1 & 7.0 & 3.6 & 2.3 & 0.14 & 0.09 & 0.06 \\
\hline 9 & 18.2 & 23.3 & 18.1 & 8.5 & 6.4 & 4.5 & 0.47 & 0.27 & 0.25 \\
\hline 10 & 12.3 & 18.1 & 12.9 & 9.3 & 9.3 & 4.9 & 0.76 & 0.51 & 0.38 \\
\hline 11 & 14.9 & 22.0 & 18.7 & 8.5 & 4.3 & 1.8 & 0.57 & 0.19 & 0.10 \\
\hline 12 & 17.1 & 19.5 & 20.2 & 8.9 & 4.3 & 1.7 & 0.52 & 0.22 & 0.08 \\
\hline 13 & 25.4 & 29.2 & 24.2 & 6.3 & 4.4 & 2.1 & 0.25 & 0.15 & 0.09 \\
\hline 14 & 14.0 & 13.0 & 12.6 & 7.3 & 6.1 & 4.4 & 0.52 & 0.47 & 0.35 \\
\hline 15 & 58.7 & 55.3 & 46.2 & 5.8 & 3.7 & 2.8 & 0.10 & 0.07 & 0.06 \\
\hline 16 & 30.9 & 24.2 & 28.8 & 6.1 & 4.9 & 2.2 & 0.20 & 0.20 & 0.08 \\
\hline Mean & 29.3 & 29.7 & 27.0 & 7.4 & 5.6 & 2.9 & 0.35 & 0.24 & 0.15 \\
\hline SD & 15.8 & 13.6 & 13.4 & 1.7 & 1.8 & 1.3 & 0.21 & 0.14 & 0.12 \\
\hline
\end{tabular}


$\left.\mathrm{He} / 24 \% \mathrm{O}_{2}\right){ }^{25}$ The present study suggests that sleep-related reduction of neural respiratory drive characteristic of COPD could be offset by an increase in upper airway resistance as a consequence of coexistent OSA, in an adaptation potentially protective in nature.

It has been hypothesised that desaturation in patients with overlap syndrome would be more severe than that in patients with COPD alone because COPD and OSA can cause desaturation. ${ }^{6730}$ However, this view is mainly derived from studies of patients who had predominantly mild or moderate COPD or who were recruited from patients with OSA and obesity, ${ }^{7} 82030$ and thus may not represent a clinical cohort of patients with severe COPD. However, a recent cohort study of non-obese patients with severe COPD showed that the number of patients with COPD alone who required oxygen supplementation was similar to that in those with overlap syndrome, ${ }^{9}$ suggesting the prevalence of oxygen desaturation is similar between patients with COPD alone and patients with overlap syndrome. In the present study we found that mean oxygen saturation and minimal oxygen saturation during overnight sleep were similar in patients with or without overlap syndrome. Moreover, although patients with coexistent OSA and severe COPD usually have brief periods of desaturation, prolonged desaturation $\left(\mathrm{SaO}_{2}<90\right.$ for longer than $\left.5 \mathrm{~min}\right)$ occurred more often in patients with severe COPD alone than those with overlap syndrome (see online supplementary table E-2). This finding may be clinically significant for the management of patients with overlap syndrome. If sleep-related hypoventilation or desaturation in patients with severe COPD had been worsened by coexistent OSA, one would have to be cautious with nutritional supplements which may raise BMI in patients with COPD. In contrast, the present study suggests that when patients with severe COPD develop mild or moderate OSA, a sleep-related reduction of neural respiratory drive as a consequence of COPD would be relieved because of increased upper airway resistance, preventing ventilation from further decreasing. The observation that $16 \%$ of patients with COPD alone developed significant oxygen desaturation but none of patients with an overlap syndrome developed a significant desaturation may give a hint that if patients with severe COPD develop mild or moderate OSA, oxygen desaturation would not necessarily be worsen. This interesting finding is in line with the recent report that the clinical outcome in end-stage patients with overlap syndrome is better than those with COPD alone. ${ }^{31}$ Nevertheless, we note that pathophysiological change in patients with overlap syndrome of severe COPD and mild OSA might differ from those with mild COPD and severe OSA; in addition variation on this spectrum may differ between western patients in whom OSA is more driven by obesity and Asian patients (as studied here) in whom craniofacial morphometry may be more relevant.

In conclusion the mechanism underlying the reduction of ventilation at stage 2 sleep in patients with COPD alone differs from that in patients with overlap syndrome. Ventilation reduction in patients with COPD alone is mainly because of a decrease in neural respiratory drive whereas it is mainly a result of an increase in upper airway resistance in patients with overlap syndrome.

\footnotetext{
Author affiliations

${ }^{1}$ State Key Laboratory of Respiratory Disease, Guangzhou Medical University, Guangzhou, China

${ }^{2}$ Jiangsu Provincial Official Hospital, Nanjing, China

${ }^{3}$ Department of Respiratory Medicine, Second Affiliated Hospital of Soochow University, Suzhou, China

${ }^{4}$ Faculty of Life Sciences and Medicine, King's College London, London, UK
}

${ }^{5}$ NIHR Respiratory Biomedical Research Unit, The Royal Brompton and Harefield NHS Foundation Trust and Imperial College, Royal Brompton Hospital, London, UK

Contributors Conception and design: $\mathrm{BH}, \mathrm{GL}, \mathrm{SX}, \mathrm{JS}, \mathrm{JM}, \mathrm{MP}, \mathrm{YL}$; analysis and interpretation: $\mathrm{BH}, \mathrm{GL}, \mathrm{SX}, \mathrm{RC}$; drafting the manuscript for important intellectual content: BH, GL, SX, RC, JS, JM, MP, YL.

Funding The work was supported by National Natural Science Foundation of China (NSFC No. 81120108001 and 81270143). Professor Polkey's contribution to this project was supported by the NIHR Respiratory Biomedical Research Unit at the Royal Brompton and Harefield NHS Foundation Trust and Imperial College, London UK, who part funded his salary.

Competing interests None declared.

Patient consent Obtained.

Ethics approval The Ethics Committee of the First Affiliated Hospital of Guangzhou Medical University.

Provenance and peer review Not commissioned; externally peer reviewed.

Open Access This is an Open Access article distributed in accordance with the Creative Commons Attribution Non Commercial (CC BY-NC 4.0) license, which permits others to distribute, remix, adapt, build upon this work non-commercially, and license their derivative works on different terms, provided the original work is properly cited and the use is non-commercial. See: http://creativecommons.org/ licenses/by-nc/4.0/

\section{REFERENCES}

1 Lewis CA, Fergusson W, Eaton T, et al. Isolated nocturnal desaturation in COPD: prevalence and impact on quality of life and sleep. Thorax 2009;64:133-8.

2 Luo YM, He BT, Wu YX, et al. Neural Respiratory Drive and Ventilation in Patients with Chronic Obstructive Pulmonary Disease during Sleep. Am J Respir Crit Care Med 2014;190:227-9.

3 Morrell MJ, Harty HR, Adams L, et al. Breathing during wakefulness and NREM sleep in humans without an upper airway. J App/ Physiol 1996;81:274-81.

4 Xiao SC, He BT, Steier J, et al. Neural respiratory drive and arousal in patients with obstructive sleep apnea hypopnea. Sleep 2015;38:941-9.

5 Luo YM, Wu HD, Tang J, et al. Neural respiratory drive during apnoeic events in obstructive sleep apnoea. Eur Respir J 2008;31:650-7.

6 McNicholas WT. Chronic obstructive pulmonary disease and obstructive sleep apnea: overlaps in pathophysiology, systemic inflammation, and cardiovascular disease. Am J Respir Crit Care Med 2009;180:692-700.

7 Marin JM, Soriano JB, Carrizo SJ, et al. Outcomes in patients with chronic obstructive pulmonary disease and obstructive sleep apnea: the overlap syndrome. Am J Respir Crit Care Med 2010;182:325-31.

8 Lacedonia D, Carpagnano GE, Aliani M, et al. Daytime PaO2 in OSAS, COPD and the combination of the two (overlap syndrome). Respir Med 2013;107:310-16.

9 Soler $\mathrm{X}$, Gaio $\mathrm{E}$, Powell FL, et al. High prevalence of obstructive sleep apnea in patients with moderate to severe chronic obstructive pulmonary disease. Ann Am Thorac Soc 2015;12:1219-25.

10 Luo YM, Tang J, Jolley C, et al. Distinguishing obstructive from central sleep apnea events: diaphragm electromyogram and oesophageal pressure compared. Chest 2009;135:1133-41.

11 Faisal A, Alghamdi BJ, Ciavaglia CE, et al. Common mechanisms of dyspnea in chronic interstitial and obstructive lung disorders. Am J Respir Crit Care Med 2016:193:299-309.

12 Luo YM, Moxham J, Polkey MI. Diaphragm electromyography using an oesophageal catheter: current concepts. Clin Sci 2008;115:233-44.

13 Berry RB, Budhiraja R, Gottlieb DJ, et al., American Academy of Sleep Medicine. Rules for scoring respiratory events in sleep: update of the 2007 AASM Manual for the Scoring of Sleep and Associated Events. Deliberations of the Sleep Apnea Definitions Task Force of the American Academy of Sleep Medicine. J Clin Sleep Med 2012:8:597-619.

14 Littner MR, McGinty DJ, Arand DL. Determinants of oxygen desaturation in the course of ventilation during sleep in chronic obstructive pulmonary disease. Am Rev Respir Dis 1980;122:849-57.

15 Hudgel DW, Martin RJ, Capehart M, et al. Contribution of hypoventilation to sleep oxygen desaturation in chronic obstructive pulmonary disease. J Appl Physiol Respir Environ Exerc Physiol 1983;55:669-77

16 Catterall JR, Calverley PM, MacNee W, et al. Mechanism of transient nocturnal hypoxemia in hypoxic chronic bronchitis and emphysema. J Appl Physiol 1985:59:1698-703.

17 Werchowski JL, Sanders MH, Costantino JP, et al. Inductance plethysmography measurement of CPAP-induced changes in end-expiratory lung volume. J App/ Physiol 1990;68:1732-8

18 Becker HF, Piper AJ, Flynn WE, et al. Breathing during sleep in patients with nocturnal desaturation. Am J Respir Crit Care Med 1999:159:112-18. 


\section{Sleep}

19 Ballard RD, Clover CW, Suh BY. Influence of sleep on respiratory function in emphysema. Am J Respir Crit Care Med 1995;151:945-51.

20 Sanders MH, Newman AB, Haggerty CL, et al., Sleep Heart Health Study. Sleep and sleep-disordered breathing in adults with predominantly mild obstructive airway disease. Am J Respir Crit Care Med 2003;167:7-14.

21 Krachman SL, Tiwari R, Vega ME, et al. Effect of emphysema severity on the Apnea-Hypopnea Index in smokers with obstructive sleep apnea. Ann Am Thorac Soc 2016;13:1129-35.

22 Zhong N, Wang C, Yao W, et al. Prevalence of chronic obstructive pulmonary disease in China: a large, population-based survey. Am J Respir Crit Care Med 2007; 176:753-60.

23 Lee RW, Vasudavan S, Hui DS, et al. Differences in craniofacial structures and obesity in Caucasian and Chinese patients with obstructive sleep apnea. Sleep 2010;33:1075-80.

24 Morgenstern C, Schwaibold M, Randerath W, et al. Comparison of upper airway respiratory resistance measurements with the oesophageal pressure/airflow relationship during sleep. Conf Proc IEEE Eng Med Biol Soc 2011;2011:3205-8.
25 O'Donoghue FJ, Catcheside PG, Eckert DJ, et al. Changes in respiration in NREM sleep in hypercapnic chronic obstructive pulmonary disease. J Physiol (Lond) 2004;559:663-73.

26 Meurice JC, Marc I, Sériès F. Influence of sleep on ventilatory and upper airway response to $\mathrm{CO} 2$ in normal subjects and patients with COPD. Am J Respir Crit Care Med 1995;152:1620-6.

27 Jolley CJ, Luo YM, Steier J, et al. Neural respiratory drive in healthy subjects and in COPD. Eur Respir J 2009;33:289-97.

28 Sinderby C, Beck J, Spahija J, et al. Voluntary activation of the human diaphragm in health and disease. J Appl Physiol 1998;85:2146-58.

29 Luo YM, Qiu ZH, Wu HD, et al. Neural drive during continuous positive airway pressure (CPAP) and pressure relief CPAP. Sleep Med 2009;10:731-8.

30 Chaouat A, Weitzenblum E, Krieger J, et al. Association of chronic obstructive pulmonary disease and sleep apnea syndrome. Am J Respir Crit Care Med 1995;151:82-6.

31 Patout M, Ramsay M, Mackie M, et al. Home mechanical ventilation (HMV): setup and outcome in European (abstract). Eur Respir J 2015;46(Suppl 59):OA4780. 